\title{
Comparison of Statistical, Graphical, and Wavelet Transform Analyses for Rainfall Trends and Patterns in Badulu Oya Catchment, Sri Lanka
}

\author{
Ashika M. Ruwangika, ${ }^{1}$ Anushka Perera $\mathbb{D}^{2},{ }^{2}$ and Upaka Rathnayake $\mathbb{D}^{2}$ \\ ${ }^{1}$ Department of Physical Science and Technology, Faculty of Applied Sciences, Sabaragamuwa University of Sri Lanka, \\ Belihuloya, Sri Lanka \\ ${ }^{2}$ Department of Civil Engineering, Faculty of Engineering, Sri Lanka Institute of Information Technology, Malabe, Sri Lanka
}

Correspondence should be addressed to Upaka Rathnayake; upakasanjeewa@gmail.com

Received 4 August 2020; Revised 7 September 2020; Accepted 28 September 2020; Published 21 October 2020

Academic Editor: Shamsuddin Shahid

Copyright ( 92020 Ashika M. Ruwangika et al. This is an open access article distributed under the Creative Commons Attribution License, which permits unrestricted use, distribution, and reproduction in any medium, provided the original work is properly cited.

\begin{abstract}
Climate change has adversely influenced many activities. It has increased the intensified precipitation events in some places and decreased the precipitation in some other places. In addition, some research studies revealed that the climate change has moved seasons in the temporal scale. Therefore, the changes can be seen in both spatial and temporal scales. Thus, analyzing climate change in the localized environments is highly essential. Rainfall trend analysis in a localized catchment can improve many aspects of water resource management not only to the catchment itself but also to some of the related other catchments. This research is carried to identify the rainfall trends in Badulu Oya catchment, Sri Lanka. The catchment is important as it is in the intermediate climate zone and rich in agricultural productions. Four rain gauges (namely, Badulla, Kandekatiya, Lower Spring Valley, and Ledgerwatte Estate) were used to analyze the rainfalls in the resolutions of monthly, seasonally, and annually. 30-year monthly cumulative rainfall data for the above four gauging stations are analyzed using various standard tests. Nonparametric tests including Mann-Kendall test and sequential Mann-Kendall test and innovative trend analysis methods are used to identify the potential rainfall trends in Badulu Oya catchment. In addition, continuous wavelet transforms and discrete wavelet transforms tests are carried out to check the patterns on rainfall to the catchment. The trend analysis methods are compared against each other to identify the better technique. The results reveal that the nonparametric Mann-Kendall test is powerful to produce the statistically significant rainfall trends in qualitative and quantitative manner. Mann-Kendall analysis shows a positive trend to Ledgerwatte Estate in monthly (3.7 $\mathrm{mm}$ in February and $7.4 \mathrm{~mm}$ in October), seasonal $\left(6.9 \mathrm{~mm}\right.$ in the $2^{\text {nd }}$ intermonsoon), and annual (3 mm annually) scales. However, the analysis records one decreasing rainfall trend to Kandekatiya ( $8.1 \mathrm{~mm}$ in December) only in monthly scale. Nevertheless, it was found that the graphical method can be easily used in qualitative analysis, while discrete wavelet transformations are efficient in identifying the rainfall patterns effectively.
\end{abstract}

\section{Introduction}

Catchments in intermediate climatic zones are interesting to analyze for the water resources management [1]. These zones are neither the wet zones, where they have plenty of water resources, nor the arid zones, where there are enough water scarcities. Water sustainability can be achieved in these intermediate zones, only if the water resources are properly managed. The availability of water resources in these intermediate zones is highly influenced by the seasonal rainfall. However, there are many arguments on the changes and variations in seasonal rainfall in most of the countries due to ongoing climate changes.

When some countries have more than the usual annual rainfalls and rainfall intensities (sometimes snowfalls) [2-6], some other countries face more arid times leading to water scarcities [7-9]. Therefore, it is highly important to understand the spatial variation in various climatic 
characteristics due to ongoing climate change in the local resolutions rather the global resolution. The best would be the catchment scale spatial resolution; thus, the local climate change scenarios can be easily acknowledged. As a result, the required adaptation processes (whether they are structural or nonstructural) in the catchment scales can be implemented.

Researchers used several methods to understand climate change and its impact on the precipitation (rainfall). Precipitation has taken more attention due to its driving capacity of the hydrological cycle, which is the life of the Earth $[10,11]$. Among many empirical climate models, past recorded climate data analyses have taken much attention from most of the researchers. This can be due to the usual unpredictability of the climate scenarios; however, there may be some periodic characteristics behind the measured data. Therefore, statistical tests are frequently used in measured climate data analyses. Parametric and nonparametric statistical tests are used to detect climatic trends. Even though the parametric tests $(t$-test and linear regression) are powerful in statistical analyses, they need the tested data to be independent and normally distributed [12]. However, most of the climatic data are not normally distributed. Therefore, nonparametric tests like Mann-Kendall test [13-16] and sequential Mann-Kendall test [17-21] are common in climatic trend detection. Not only the statistical analysis but also some innovative methods like innovative trend analysis techniques [22] [23-26] are often used to identify the trends in climatic time series.

In addition to the trend analysis, wavelet analysis [27-31] can be observed in the climatic time series analysis for pattern detection. Various methods have their own advantages and disadvantages; however, a collection of these tests would receive a better outcome to the stakeholders. Therefore, comparison analyses using a collection of these parametric, nonparametric, innovative trend analysis, and wavelet analysis are common [24, 32-34]. However, the application of these climatic analyses is now moved to a localized area rather to the globe. As it was stated, identifying localized climatic trends are important in many planning activities [35-38]. Even though these rainfall trends may not perfectly be identified, acceptable identification is highly desirable for future planning activities, like irrigation scheduling, water supply systems design, and upgrading. Therefore, it is understood to be essential to a catchment, which is based on agriculture, not only to supply the food for the localized environment but to the whole Sri Lanka. Badulu Oya catchment in Sri Lanka is a catchment in the intermediate climate zone; however, it receives a significant amount of annual rainfall to cater the paddy and vegetable cultivation. The catchment produces more than $25 \%$ of the country's vegetable need. Several related research can be found in the context of Sri Lanka [24, 39-43]. However, no research is found in the literature for identifying the rainfall trends in the catchment to guide the planners. Therefore, the presented work herein reveals the rainfall trends to Badulu Oya catchment. Several methods, including the Mann-Kendall test, sequential Mann-Kendall test, innovative trend analysis, and wavelets, are used to analyze the rainfall trends, and the results are compared to each other in seeking the better method. The advantages and drawbacks of each method are discussed in relevant sections, and the importance of such study is well established and stated in Discussion.

\section{Study Area: Badulu Oya Catchment}

Badulu Oya starts from Namunukula mountain range and flows from the eastern slopes of the central highlands to reach Mahaweli River, which is the longest river in Sri Lanka. It is one of the most important tributaries of the Mahaweli River. The terrain, in which Badulu Oya flows, is in the intermediate climatic zone of the country [44], and therefore, a significant amount of annual rainfall is seen in the catchment $(1500-2000 \mathrm{~mm})$. The catchment receives its major rainfall in the months of October to March (during the northeast monsoon and $1^{\text {st }}$ intermonsoon), whereas it has a drier period during April-September months. However, convection rainfalls are common during the drier months. Therefore, the catchment has a rich water capacity.

The catchment area of Badulu Oya is around $318 \mathrm{~km}^{2}$ (refer Figure 1), and it is placed adjacent to the Uma Oya catchment from its left and Gal Oya catchment from its right. Intensive agricultural activities are taken place in Badulu Oya catchment [46]; therefore, various land-uses over the time can be observed. Some of the forest areas have been changed to urban, suburban, and agricultural areas over the last decades [46]. Most of the forest areas were converted into tea plantations during the British ruling era [47], while other land-use activities have been happened during the $20^{\text {th }}$ century. Therefore, the surface water and groundwater availability have been severely impacted. Hence, it is timely important to observe the rainfall trends in the catchment using the recorded data.

Four rain gauging stations including Badulla $(6.980 \mathrm{~N}$, $81.050 \mathrm{E})$, Lower Spring Valley $(6.920 \mathrm{~N}, 81.10 \mathrm{E})$, Ledgerwatte Estate $(7.030 \mathrm{~N}, 81.020 \mathrm{E})$ and Kandekatiya $(7.170 \mathrm{~N}$, $81.020 \mathrm{E}$ ) were selected for this analysis.

\section{Nonparametric Tests in Climatic Trends}

Nonparametric tests are widely used to identify climate trends [48-51]. Nonparametric tests are widely used not only to identify the climatic trends but also to detect the trends in other temporal variations like stream flow trends $[52,53]$ and water quality trends in streams and rivers [54]. Several nonparametric tests can be found in the literature including Mann-Kendall test, Spearman's rho test $[55,56]$, and Hotelling-Pabst test $[57,58]$. However, Mann-Kendall test and its modifications are widely used in the literature for trend analysis $[41,59,60]$.

3.1. Mann-Kendall Test and Sen's Slope Estimator. Mann-Kendall test is used to identify monotonically increasing and decreasing trends in a climate data series. The test was initially proposed by Mann [61] and improved by Kendall [62]. The test was further improved to consider the seasonal effects by Hirsch et al. [63]. The test calculates Kendall's tau between two data samples based on the ranks. These samples were assumed to be independent. The alternative hypotheses from the test have three outcomes, 

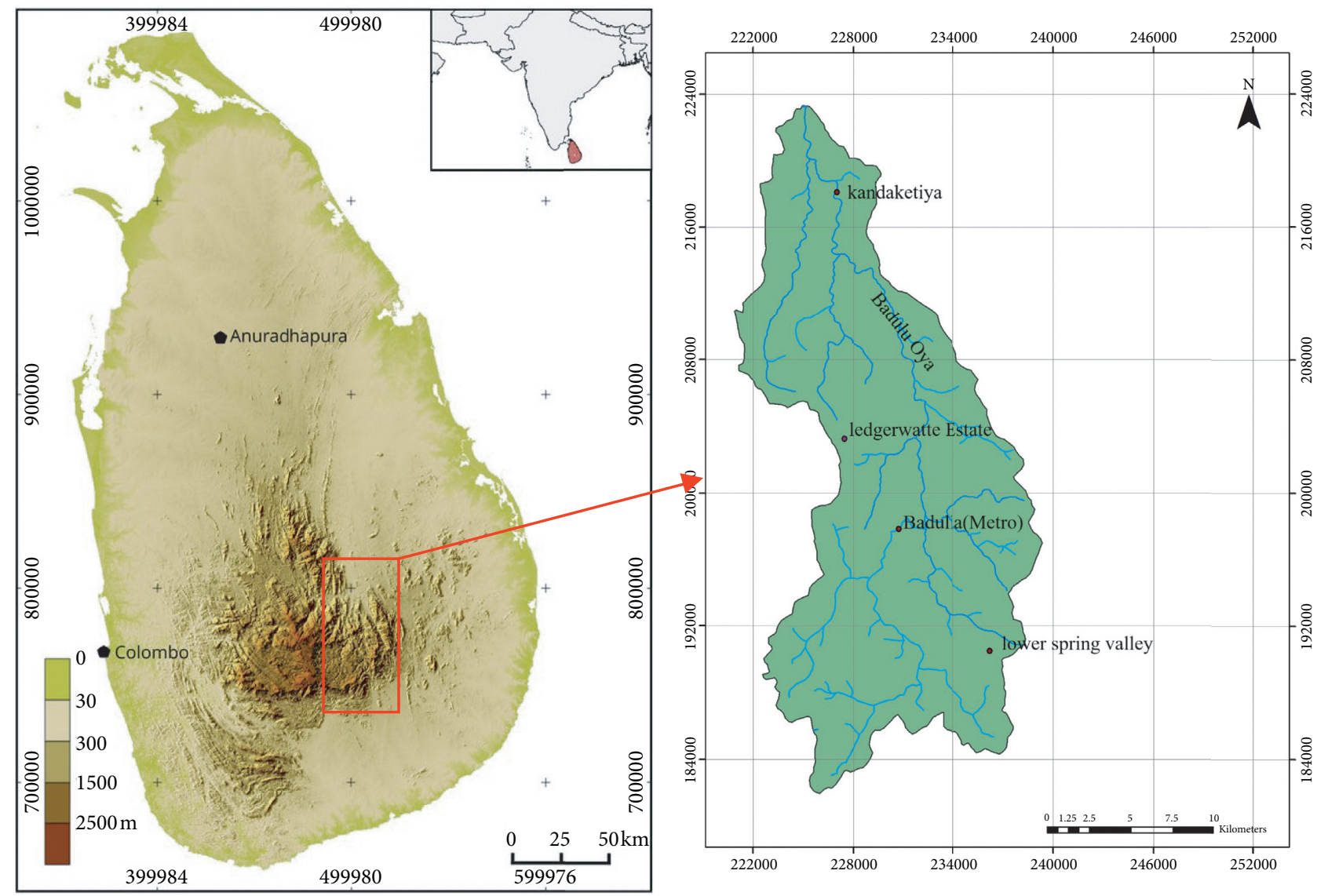

FIgure 1: Badulu Oya catchment (Sri Lanka topography map was extracted from [45]).

negative trend, no trend, and positive trend. The mathematical formulations of calculating Mann-Kendall statistics $S$, variance $V(S)$, and standard test statistics $Z_{\mathrm{MK}}$ are given in the following equations:

$$
\begin{gathered}
S=\sum_{i=1}^{n-1} \sum_{j=i+1}^{n} \operatorname{sgn}\left(x_{j}-x_{i}\right), \\
\operatorname{sgn}\left(x_{j}-x_{i}\right)= \begin{cases}+1, & \text { if }\left(x_{j}-x_{i}\right)>0, \\
0, & \text { if }\left(x_{j}-x_{i}\right)=0, \\
-1, & \text { if }\left(x_{j}-x_{i}\right)<0,\end{cases} \\
V(S)=\frac{1}{18}[n(n-1)(2 n+5) \\
\left.-\sum_{p=1}^{q} t_{p}\left(t_{p}-1\right)\left(2 t_{p}+5\right)\right], \\
Z_{\mathrm{MK}}= \begin{cases}\frac{S-1}{\sqrt{V(S)}}, & \text { if } S>0, \\
0, & \text { if } S=0, \\
\frac{S+1}{\sqrt{V(S)}}, & \text { if } S<0,\end{cases}
\end{gathered}
$$

where $x_{i}$ and $x_{j}$ are chronological time series observations, $n$ is the length of the time series, $t_{p}$ is the number of ties for the $p^{\text {th }}$ value, and $q$ is the number of tied values in the above stated equations. An upward trend in the climatological series is given by a positive $\mathrm{Z}_{\mathrm{MK}}$ value, whereas a downward trend is given by a negative $Z_{M K}$ value. More details of the Mann-Kendall test can be found in Ahamed et al. [55] and Rathnayake [24].

Sen's slope estimator is usually used to quantify the meteorological trends identified from Mann-Kendall test [13-16]. Sen's slope estimator calculated the gradient of the trend line; therefore, it presents the linear magnitude of the trend. Sen's slope calculates the slopes $\left(m_{i}\right)$ of all data pairs considered using the following equation:

$$
m_{i}=\frac{x_{j}-x_{k}}{j-k}, \quad \text { for } i=1,2, \ldots, N,
$$

where $N$ is the number of data points in the climate time series and $x_{j}$ and $x_{k}$ are data values at time $j$ and $k$ (where $j>k$ ), respectively. The mean value of all slopes is Sen's slope and calculated as given in the following equation:

$$
\beta= \begin{cases}m_{((N+1 / 2))}, & \text { if } N \text { is odd } \\ \frac{1}{2}\left(m_{(N / 2)}+m_{((N+1 / 2))}\right), & \text { if } N \text { is even. }\end{cases}
$$


The trend can be detected as an upward or downward trend based on the + or-behavior of the $\beta$.

3.2. Sequential Mann-Kendall Test (SQMK Test). Not only the monotonic trend and its magnitude but also the starting time of the trend is important. In addition, identification of the changes in trends over the time is highly important [64]. Therefore, the sequential Mann-Kendall test is widely used in such cases [17-21]. Sneyers [65] has introduced sequential and partial values from the usual Mann-Kendall test. The test sets up two climatic time series: one for the progressive series $(u(t))$ and the other one is for the backward series $\left(u^{\prime}(t)\right)$. The $u(t)$ is a standardized variable, which has a zero mean and unit standard deviation. The test also considers the relative values of all terms in the time series. The following steps and equations (7)-(10)) give the mathematical forms of the SQMK test.

The values of annual mean time series $\left(x_{j}\right)$ are compared against the time series $\left(x_{k}\right)$, and they are denoted by $n_{j}$, when $x_{j}>x_{k}$. The test statistics $\left(t_{j}\right)$ is calculated using the following equation:

$$
t_{j}=\sum_{1}^{j} n_{j} .
$$

Mean $\left(E\left(t_{j}\right)\right)$ and the variance $\left(V\left(t_{j}\right)\right)$ of the $t_{j}$ are then calculated by the following equations:

$$
\begin{aligned}
E\left(t_{j}\right) & =\frac{j(j-1)}{4}, \\
V\left(t_{j}\right) & =\frac{j(j-1)(2 j+5)}{72} .
\end{aligned}
$$

Finally, the $u(t)$ values are calculated using the following equation:

$$
u(t)=\frac{t_{j}-E\left(t_{j}\right)}{\sqrt{V\left(t_{j}\right)}} .
$$

The same procedure is repeated for the $u^{\prime}(t)$ time series using backward data. The intersection of the $u(t)$ and $u^{\prime}(t)$ illustrates the stating of the climatic trend. More details of the SQMK test can be found in Zarenistanak et al. [66].

\section{Graphical Trend Analysis (Innovative Trend Analysis)}

Sen [67] has introduced an innovative but very simple method to detect the trends in time series. The technique was applied to many climates related research studies in identifying trends [22-26]. However, the technique only proposes a qualitative analysis without any quantitative or numerical significance of the identified trend. The test simply checks the comparative analysis of two halves of the time series prepared at ascending order. The main climatic data set is first divided into two halves and arranged them in the ascending order. These two sets are compared against each other, and there is no trend if the second half aligns in $\pm 5 \%$ of $45^{\circ}$ degree line drawn to data series. However, if the second half aligns above the $5 \%$ of the $45^{\circ}$ degree line, a positive trend is proposed. In contrast, if the second half aligns below the $-5 \%$ of the $45^{\circ}$ degree line, a negative trend is proposed. More information on this method can be found in Sen [67].

\section{Wavelet Transformation}

Wavelet transformation is a relatively new tool, which is widely used to detect the climatic trends $[64,68]$. Not only in rainfall trends but also wavelet analysis is popular in many other trend detections, including freak waves in the ocean [69], water levels in rivers and reservoirs [79], and droughts [70]. A time series can be easily decomposed into several smaller time series based on time and frequency. Climatic trends, periodicity, various discontinuities, and changing points in climate series can be detected from wavelet transformation analysis [27-31]. Fourier analysis is used to break a signal into smaller but smooth sinusoids. A wavelet is a mathematical expression to localize the function in the spatial and temporal scales. Continuous and discrete wavelet transforms are two types of wavelet analysis used in the literature to identify the climatic trends.

5.1. Continuous Wavelet Transforms (CWTs). Continuous wavelet transforms use discrete wavelets in the continuous time scale $(x(t))$. Mathematically, the wavelet function $(\Psi(\eta))$ in CWT can be represented as given in equations (11)-(12). More information on these can be found in Chen et al. [71], Nalley et al. [72], and Partal and Küçük [30] study:

$$
\Psi(\eta)=\Psi\left(s^{*}, \gamma\right)=\frac{1}{\sqrt{s^{*}}} \Psi \frac{t-\gamma}{s^{*}},
$$

where $\eta, \gamma$, and $s^{*}$ are the nondimensional parameter and the translation factor (time shift) of the wavelet over the time series and the wavelet scale, respectively. The wavelet coefficients $\left(W_{\Psi}\left(s^{*}, \gamma\right)\right)$ can be found from equation (12). $\Psi^{*}$ is the complex conjugate function. A scalogram can be produced if the translation factor and the wavelet scale changed smoothly with the time. Therefore, calculations can be done to identify the amplitude of a particular scale and its fluctuations with time:

$$
W_{\Psi}\left(s^{*}, \gamma\right)=\frac{1}{\sqrt{s^{*}}} \int_{-\infty}^{\infty} x(t) \Psi^{*}\left(\frac{t-\gamma}{s^{*}}\right) \mathrm{dt} .
$$

5.2. Discrete Wavelet Transforms (DWTs). CWT can be effectively used to identify specific event, which is not obvious; however, construction of CWT is more complex [72]. In addition, CWT produces many coefficients and makes the problem more complicated. Therefore, discrete wavelet transforms (DWTs) are popular in trend identification. DWT simplifies the problem; nevertheless, they produce accurate and reliable answers [30]. DWT uses a dyadic calculation procedure; thus, it simplifies the problem [73]. Discrete wavelet transforms can be mathematically 
represented in the following equations (refer equations (13) and (14)):

$$
\Psi_{(a, b)}\left(\frac{t-\gamma}{s^{*}}\right)=\frac{1}{\left(s_{0}\right)^{a / 2}} \Psi\left(\frac{t-b \gamma_{0} s_{0}^{a}}{s_{0}^{a}}\right),
$$

where $\Psi, \gamma_{0}$, and $s_{0}$ are mother wavelet, translation of the wavelet, and dilation step $(>1)$, respectively. $a$ and $b$ are integers which are used to represent the dilation and translation of the wavelet. The wavelet coefficients are calculated using the following equation:

$$
W_{\Psi}(a, b)=\frac{1}{2^{a / 2}} \sum_{t=0}^{N-1} x(t) \Psi\left(\frac{t}{2^{a}}-b\right) .
$$
[72].

More information on DWT can be found in Nalley et al.

\section{Climatic Analysis in Badulu Oya Catchment}

As it was stated in Section 2, four rain gauging stations (Badulla, Lower Spring Valley, Ledgerwatte Estate, and Kandekatiya) were selected to the analysis. These stations were selected due to the data scarcity of the catchment. Monthly rainfall data for 30 years (Jan/1990 to Dec/2019) for the above stations were purchased from the Department of Meteorology, Sri Lanka. There are no other rainfall gauging stations in the catchment according to the Department of Meteorology, Sri Lanka. There were several other older stations in the catchment; however, they are not functioned according to the Department of Meteorology, Sri Lanka (Department of Meteorology, Sri Lanka holds the sole responsibility of meteorological data collection in the whole Sri Lanka). There were few missing data, and their percentages were minimum (Kandekatiya, 1.67\%; Ledgerwatte Estate, 1.67\%; Lower Spring Valley, 1.1\%; and Badulla, 0.28\%). Therefore, the missing data were filled using the normal ratio method. The rainfall data series were tested for the homogeneity using Pettit's test, SNHT test, and Buishand's test and found they were homogeneous. Therefore, the quality of the data series was rich.

The monthly rainfall data were sorted to four rainfall seasons (northeast monsoon, December to February; 1st intermonsoon, March to April; southwest monsoon, May to September; 2nd intermonsoon, October to November) and annual cumulative rainfalls. The rainfall data were then processed for the Mann-Kendall test in monthly, seasonal, and annual resolutions. After that, the sequential Mann-Kendall test was carried out to identify the locations of the trends in seasonal and annual resolutions. The innovative method was also processed to develop the graphical trends for monthly, seasonal, and annual resolutions for all four rain gauges.

Finally, wavelet analysis from CWT and DWT was carried out to the monthly, seasonal, and annual resolutions. Morlet wavelet and Daubechies wavelet $(\mathrm{db})$ were used to carry out the CWT and DWT analyses, respectively. Morlet wavelet is sine-shaped Gaussian, and more details on this are discussed in the relevant Results section. On the contrary,
Daubechies wavelet is commonly used in hydrometeorological studies as it has a smooth mother wavelet [74-78]. These tests were carried out in the Matlab mathematical package. The moderately large number of data points was used in this study from the monthly and annual precipitation datasets. The precipitation data were analyzed for the period 1990-2019. Therefore, there were $360(12 \times 30)$ data points for the monthly sets. First, the decomposition levels were determined to avoid unnecessary levels of data decomposition of these larger datasets. Finally, comparative analyses were conducted to identify a better technique in identifying the rainfall trends of the Badulu Oya catchment.

\section{Results and Discussion}

7.1. Mann-Kendall Trend Analysis Results. Table 1 presents the trend analysis results from the MK test. No significant trends were identified for the Badulla rain gauge for the 30year rainfall analysis in the monthly (January to December separately), seasonal (4 seasons), and annual resolutions. However, a decreasing trend was identified in Kandekatiya rain gauge for the month of December. Nevertheless, month December is treated to be one of the most rainfalls receiving months to Badulu Oya catchment. However, this trend identification was not justified in seasonal and annual trend analysis. Similar observation: however, an increasing trend in the month of May can be found for the rain gauge in Lower Spring Valley.

7.2. Sequential Mann-Kendall Trend Analysis Results. Figure 2 presents the graphical trend analysis results for annual (Figure 2(a)) and seasonal (Figures 2(b)-2(e)) from the SQMK test. The standard value of $Z$ for the significance level of 0.05 ( $p=0.05$ or $5 \%)$ is \pm 1.96 , and these boundary lines are shown in bold black straight lines of all figures. Mann-Kendall $Z$ values greater than the upper bound $(Z>1.96)$ propose an upward trend, while lower than the lower bound $(Z<-1.96)$ propose a downward trend. Figure 2(a) clearly shows an upward rainfall trend for Ledgerwatte Estate rain gauge and that is from 2007 onwards. Lower Spring Valley rain gauge also indicates $Z$ values above the upper bound in years 2011 and 2014; however, these years may not be considered for upward trends. Soon after the $Z$ value variation crosses the +1.96 line, it comes down. Therefore, it is not considered a significant upward trend. However, the other two rain gauges in Badulla and Kandekatiya have not shown upward or downward trends.

Similarly, upward trends can be seen in Figures 2(b) and 2(c). Ledgerwatte Estate shows a positive rainfall trend for northeast monsoon (in year 2011), whereas it shows an upward trend in year 2008 for the $1^{\text {st }}$ intermonsoon. In addition, Lower Spring Valley and Badulla gauging stations show upward rainfall trends in years 2003 and 2010, respectively. However, no upward or downward trends were found in southeast monsoon and $2^{\text {nd }}$ intermonsoon seasons (refer Figures 2(d) and 2(e)). 
TABle 1: Trend analysis results from the MK test.

\begin{tabular}{lcccc}
\hline $\begin{array}{l}\text { Temporal } \\
\text { resolution }\end{array}$ & Badulla & Kandekatiya & Rain gauge & Lower spring valley \\
\hline Monthly & $\begin{array}{c}\text { No } \\
\text { trend }\end{array}$ & $\begin{array}{c}\text { Decreasing trend }(8.1 \mathrm{~mm}) \\
\text { December }\end{array}$ & $\begin{array}{c}\text { Increasing trend }(4.9 \mathrm{~mm}) \\
\text { in May }\end{array}$ & $\begin{array}{c}\text { Increasing trends: } 3.7 \mathrm{~mm} \text { in February and } \\
7.4 \mathrm{~mm} \text { in October }\end{array}$ \\
\hline Seasonal & $\begin{array}{c}\text { No } \\
\text { trend }\end{array}$ & No trend & No trend & $\begin{array}{c}\text { Increasing trends }(6.9 \mathrm{~mm}) \text { in the } 2^{\text {nd }} \\
\text { intermonsoon }\end{array}$ \\
\hline Annual & $\begin{array}{c}\text { No } \\
\text { trend }\end{array}$ & No trend & No trend & Increasing trend (3 mm) \\
\hline
\end{tabular}

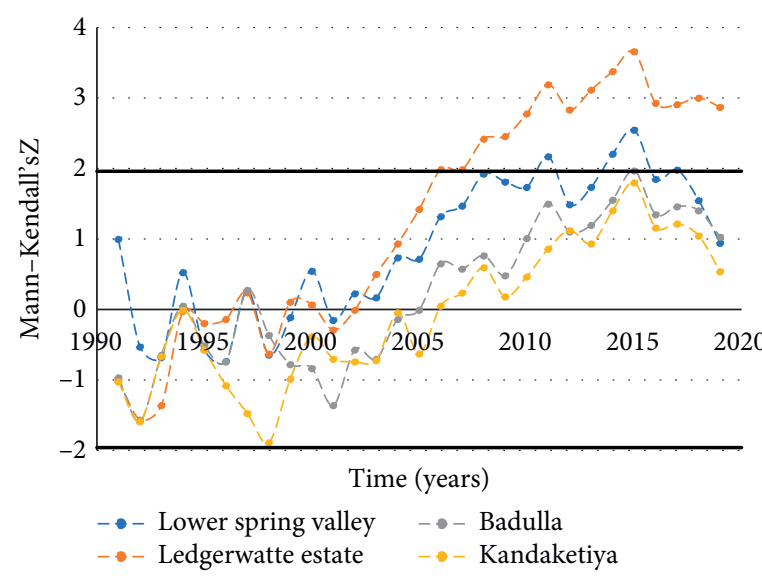

(a)

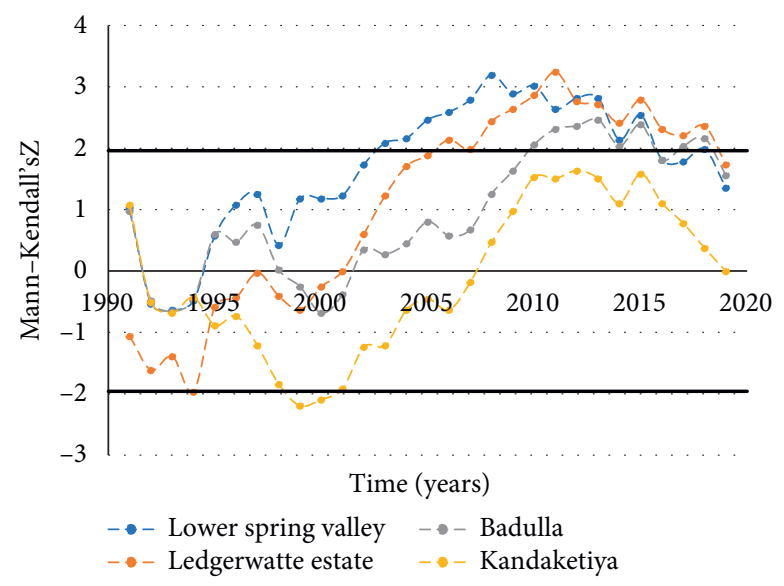

(c)

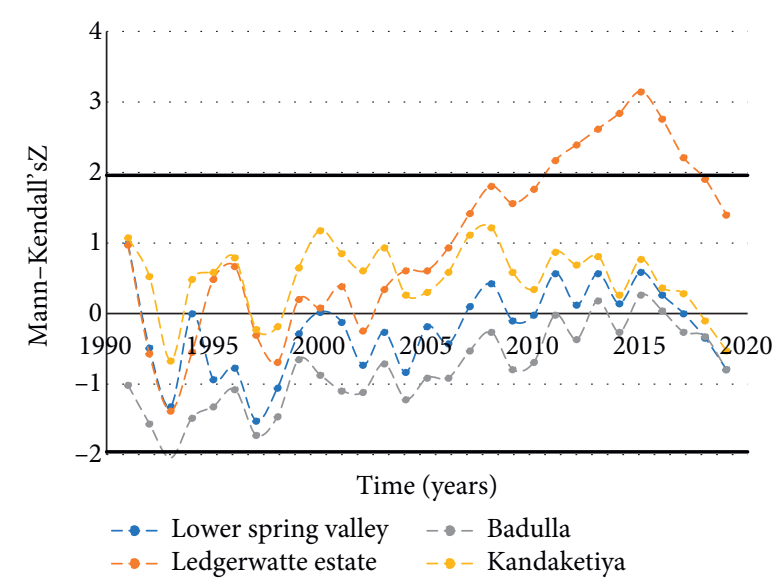

(b)

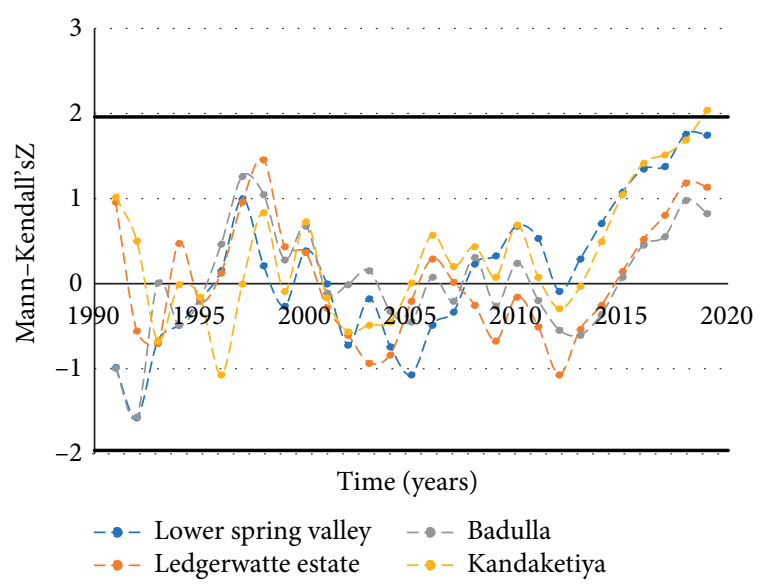

(d)

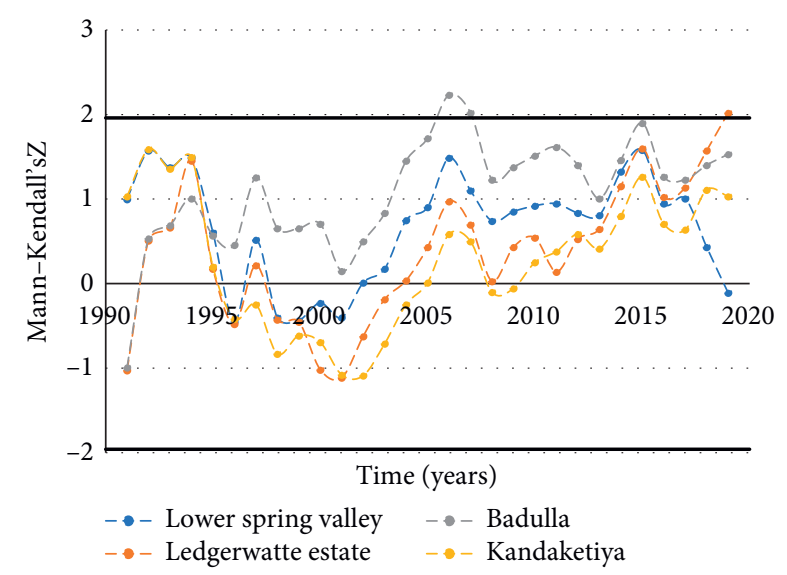

(e)

FIgURe 2: Trend analysis results from the SQMK test: (a) for annual rainfall; (b) for northeast monsoon; (c) for the $1^{\text {st }}$ intermonsoon; (d) for southwest monsoon; (e) for the $2^{\text {nd }}$ intermonsoon. 
7.3. Graphical Trend (ITA) Analysis Results. Table 2 shows trend analysis results from innovative trend analysis. Several positive trends were identified from the graphical (innovative) analysis. Monthly analysis shows positive trends in the months of March and October for Badulla. A positive trend in October was supported by the corresponding seasonal analysis where a positive trend was identified in the $2^{\text {nd }}$ intermonsoon. However, the positive trend in March was not supported by the seasonal analysis. Positive trends were found in May, October, and December for Ledgerwatte Estate, and they were supported by the seasonal and annual trends. Similar observation can be seen in Kandekatiya. However, the positive trend identified in Lower Spring Valley for May was not supported by any lower resolution rainfall patterns.

Graphical results of Badulla (Figures 3(a) and 3(b)) and Ledgerwatte Estate (Figures 3(c) and 3(d)) can be seen in Figure 3 . Identification of positive trends can be clearly seen from the data scatter and the trend line drawn for data scatter.

7.4. CWT Analysis Results. Wavelet maps are generated from the CWT analysis. The wavelet map is a graphical illustration of the continuous wavelet coefficients $C$, which signifies how closely related the wavelet with each section of the signal is. The continuous wavelet coefficients of the signals have been calculated at real, positive scales (8 voices), using the Morlet wavelet.

Morlet wavelet is often used in the rainfall analysis due to its sine-shaped Gaussian, and it has several advantages in climatic time series analysis. Gaussian shaped in the frequency domain is one advantage. It minimizes the sharp edges; therefore, the ripple effects can be ignored (these ripples can be misinterpreted as the oscillations). In addition, the results of the Morlet wavelet convolution retain the temporal resolution of the original signal. Moreover, it is computationally efficient and requires less computational cost. Therefore, many wavelet analyses tend to use Morlet wavelets.

The analyses for seasonal and annual resolutions do not show any pattern, and the data points were not enough to generate a pattern. However, if the monthly rainfall for 30 years was considered as a continuous series, interesting patterns can be observed, and they are shown in Figure 4 (4(a) $-4(d))$.

Figure 4(a) illustrates the continuous wavelet results from monthly rainfall for Badulla from January 1990 to December 2019 (360 data points). Several important observations are identified, and they are presented by part I to part VI. Times corresponding to part I to part VI are 05/1990-03/1995, 09/1998-06/2006, 01/2011-08/2015, $01 / 2018-08 / 2019,07 / 1993-06 / 2003$, and 11/2009-12/ 2017 , respectively. The periodicity was changed from 7 to 11 months in the first identified time zone (05/1990-03/ 1995). Then, a 5-month cycle was found for the 2 nd time zone, 4-month cycle for the $3 \mathrm{rd}, 7-11$ month for the 4 th, 14 -month for the 5th, and 18-month for the 6th time zone. Similarly, patterns were identified in other rain gauges, and they are shown by the corresponding boxes. Interestingly, 6 different patterns were identified from the 4 rain gauges. Closer observation of the CWT analyses gives the corresponding time slots in the patterns are somewhat similar. Therefore, this can be an indication of the similar temporal variation in the rainfalls to the Badulu Oya catchment. Nevertheless, more analysis should be required for a solid conclusion. However, cyclic patterns of the rainfall can be easily identified from the CWT analysis.

7.5. DWT Analysis Results. Figure 5 shows the decomposed level for annual and monthly rainfall time series using DWT. The monthly rainfall series was decomposed into six lower resolution levels using the DWT approach. It can be seen herein that the decomposed levels have lower frequencies. This shows the changes in periodicity. The $2,4,6,16,32$, and 64 monthly periodicities are given by $\mathrm{d} 1-\mathrm{d} 6$, as shown in Figures 5(a)-5(d). The corresponding approximation component is a6 shows the long-term change in trend. Lower frequency in a 6 approximation component represents the slowly changing component of the time series. However, the annual time series was decomposed into three detailed components $(\mathrm{d} 1-\mathrm{d} 3)$ for 2,4 , and 8 years and one approximation component (a3). The annual DWT analysis results are given in Figures 5(e) and 5(f) for Badulla and Ledgerwatte Estate, respectively. The patterns herein (DWT) are much clearer in comparison to CWT. Therefore, as usual, DWT is preferred for the analysis.

7.6. Summary of the Results. Table 3 presents the summary of various rainfall trend analysis results. Interesting findings are presented here. Several months were identified with positive trends by all tested methods, and these monthly trends were supported by the seasonal and annual trend analysis. However, other than one month from one test (Kandekatiya downward trend in December by the MK test), all other identified trends were positive trends. Similar analysis can be found in the literature, as it was already stated in a handful research studies in the context of Sri Lanka. Therefore, this analysis would be interested by the water resources planners in the country.

As it was stated, the Mann-Kendall test is a nonparametric test where the concept of it is simple. It assumes a joint distribution of the data, and therefore, the results are minimally affected due to the normality of the series. However, one of the most important drawbacks of the test is the null hypothesis. The test assumes the data are independent and identically distributed. Therefore, nonacceptance of null hypothesis in theoretical view and application view are different. It is assumed to have a trend in application, whereas the theoretical view says the data are not independent and not identically distributed. Therefore, the results of the test may be confusing.

However, on the contrary, the sequential MK test can be effectively used to detect the changing points or events in the long-term time series. Therefore, this is important in the 
TABLE 2: Results from innovative trend analysis.

\begin{tabular}{lcccc}
\hline Time series & Badulla & Ledgerwatte estate & Lower spring valley \\
\hline January & - & - & - & - \\
February & - & - & - & - \\
March & $\mathrm{Up}$ & - & $\mathrm{Up}$ & - \\
April & - & $\mathrm{Up}$ & - & - \\
May & - & - & - & - \\
June & - & - & - & - \\
July & - & - & - & - \\
August & - & - & - & - \\
September & - & $\mathrm{Up}$ & - \\
October & $\mathrm{Up}$ & - & - \\
November & - & $\mathrm{Up}$ & - \\
December & - & $\mathrm{Up}$ & - \\
Annual & - & $\mathrm{Up}$ & - \\
Northeast monsoon & - & $\mathrm{Up}$ & - \\
$1^{\text {st }}$ intermonsoon & - & - & - \\
Southwest monsoon & - & $\mathrm{Up}$ & - \\
$2^{\text {nd }}$ intermonsoon & $\mathrm{Up}$ & & - \\
\hline
\end{tabular}

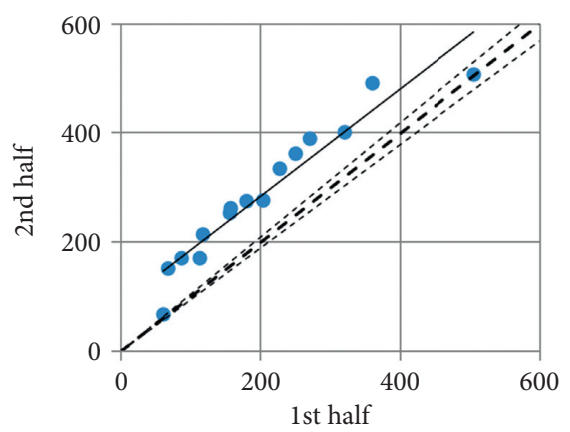

(a)

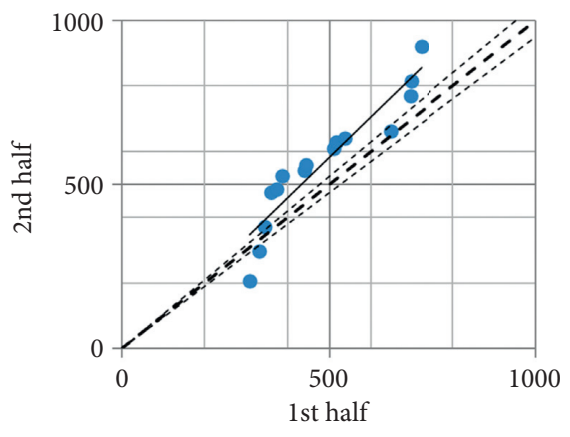

(b)

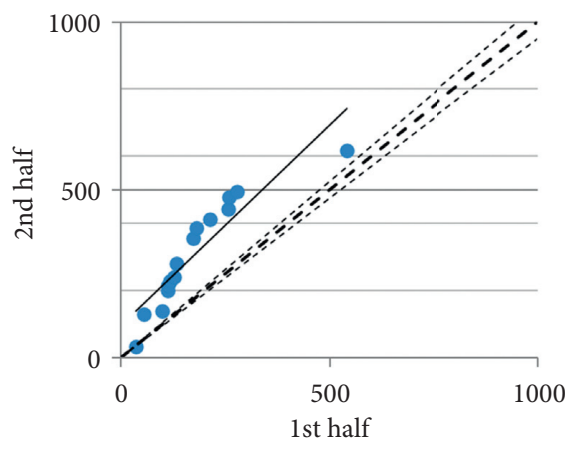

(c)

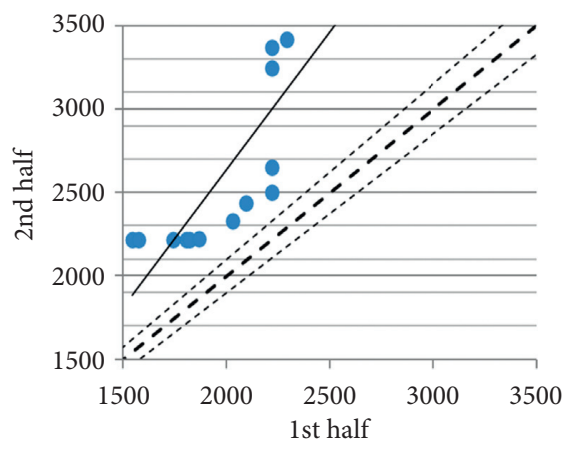

(d)

FIGURE 3: Graphical trend analysis results from ITA: (a) for Badulla-October; (b) for Badulla-2 ${ }^{\text {nd }}$ intermonsoon; (c) for Ledgerwatte Estate-October; (d) for Ledgerwatte Estate-annual.

analysis to have the potential trend from the MK test and the changing event from the SQMK test. Therefore, coupling both tests ( $M K$ and SQMK) would give a better picture to the stakeholders. In addition, ITA is much simpler than any other method in trend detention. It is, however, a qualitative analysis, rather a quantitative analysis. Therefore, researchers can use ITA as an initial step to detect the potential trends and then move to solid statistical tests for quantitative trends. Even though CWT and DWT have advantages, they are more complex analyses compared to simple statistical analyses. Therefore, the stakeholders would not be much interested, unless they are given a clear idea and the physical meaning of these CWT and DWT analyses. However, they are highly sophisticated methods in climate time series analysis in the research point of view.

Therefore, the comparison of various methods in rainfall time series analysis for Badulu Oya catchment requires much attention, depending on the stakeholders' 

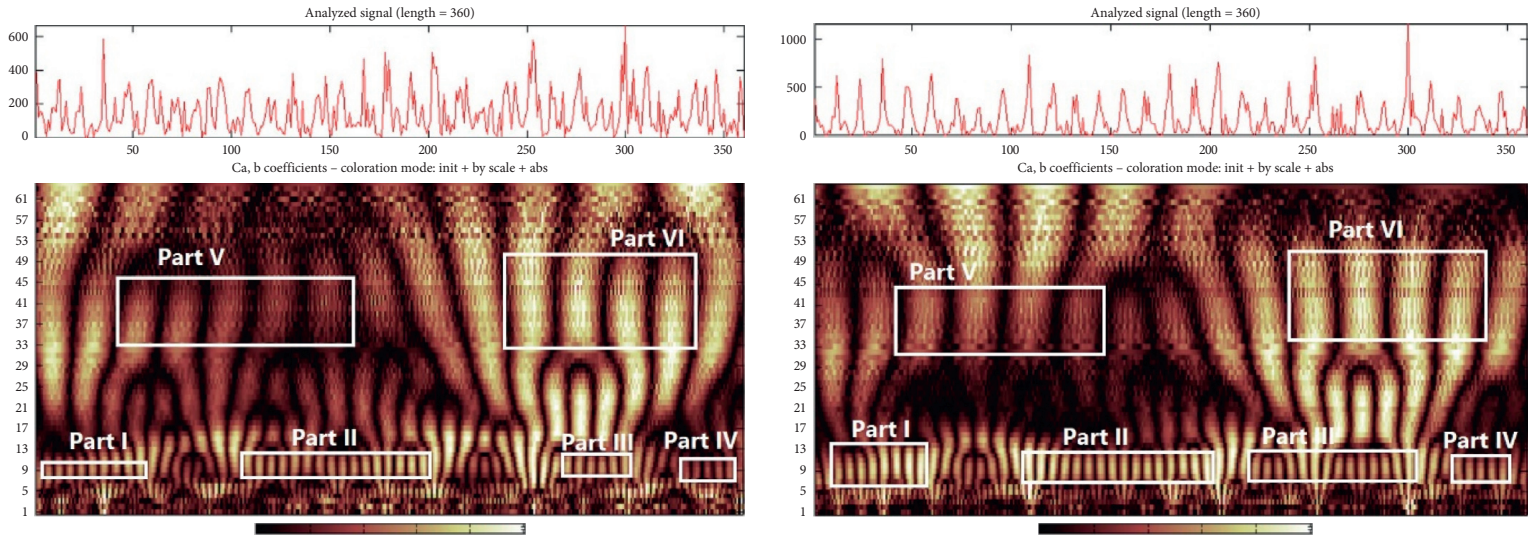

(a)

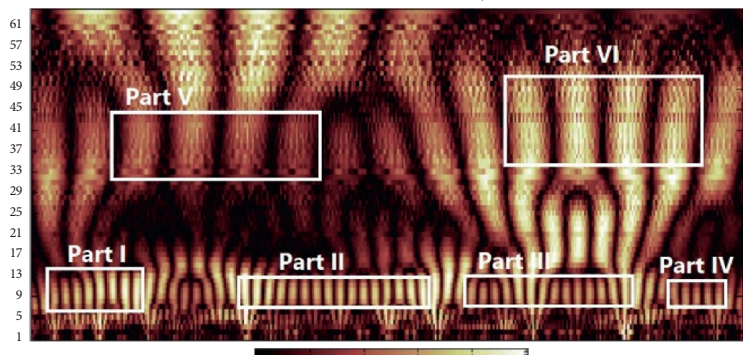

Scale of colors from MIN to MAX

(b)
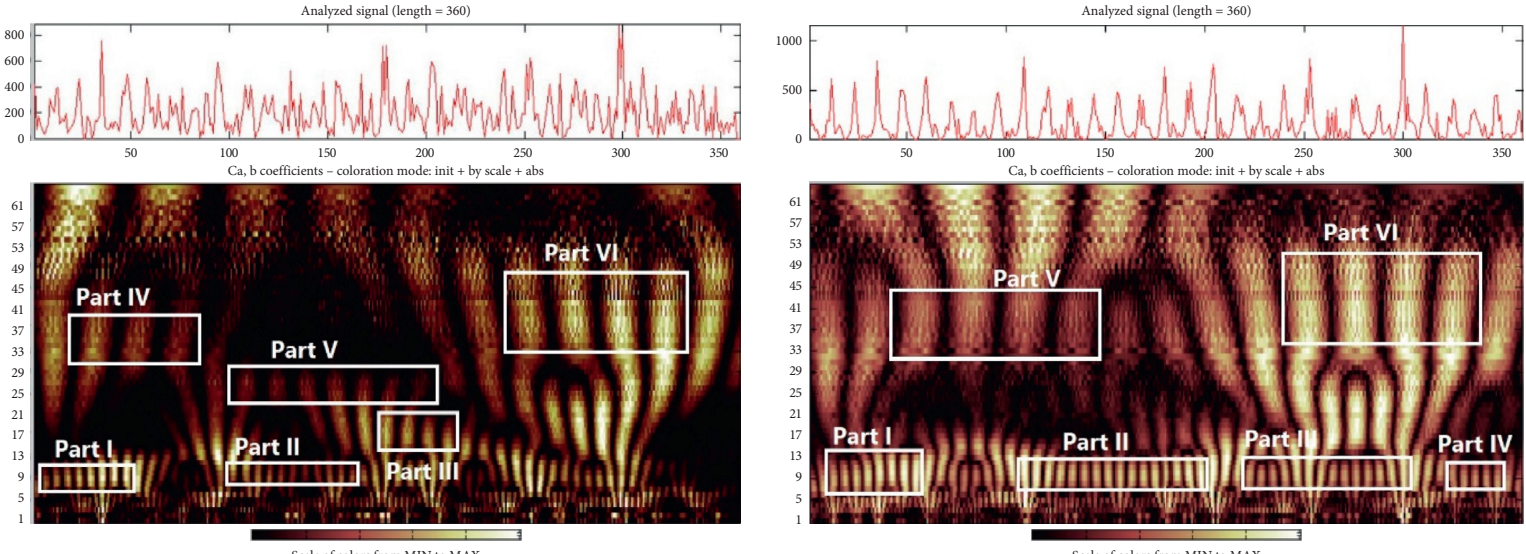

(c)

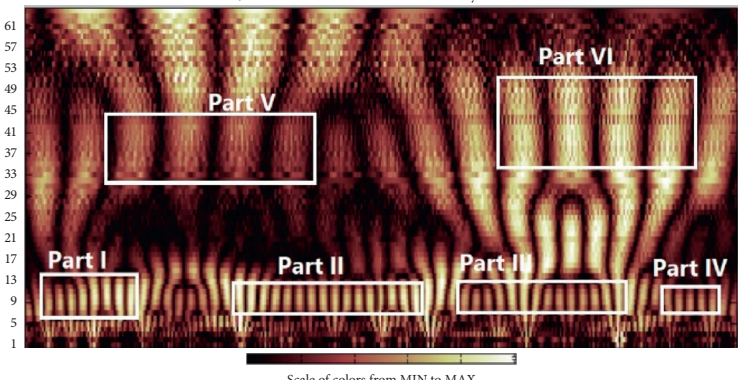

(d)

FIGURE 4: Continuous wavelet transform results for monthly rainfall: (a) for Badulla; (b) for Ledgerwatte Estate; (c) for Lower Spring Valley; (d) For Kandekatiya.

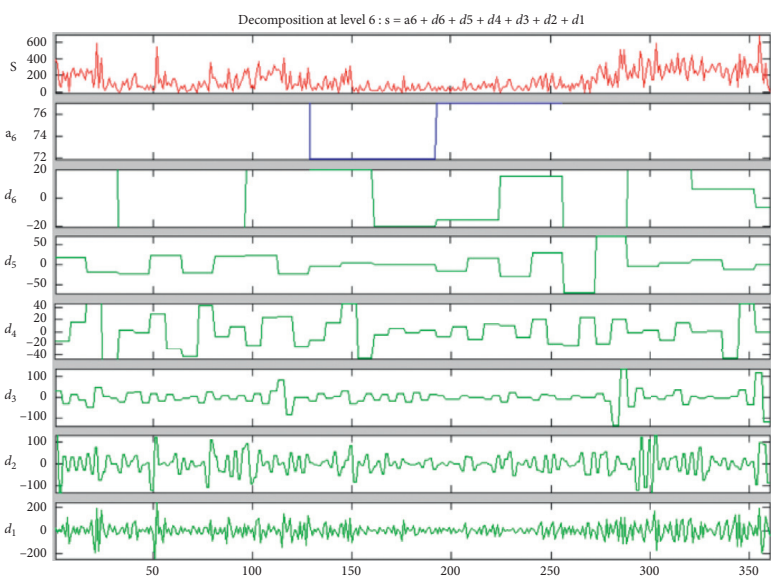

(a)

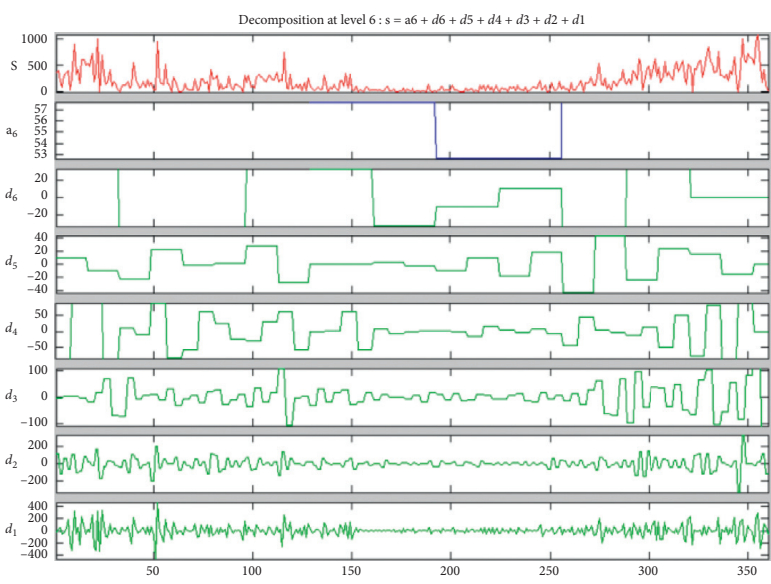

(b)

Figure 5: Continued. 


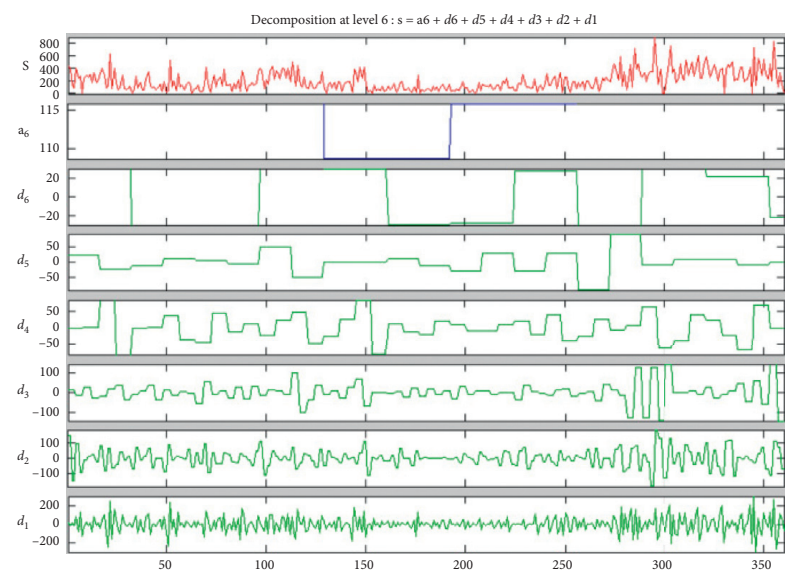

(c)

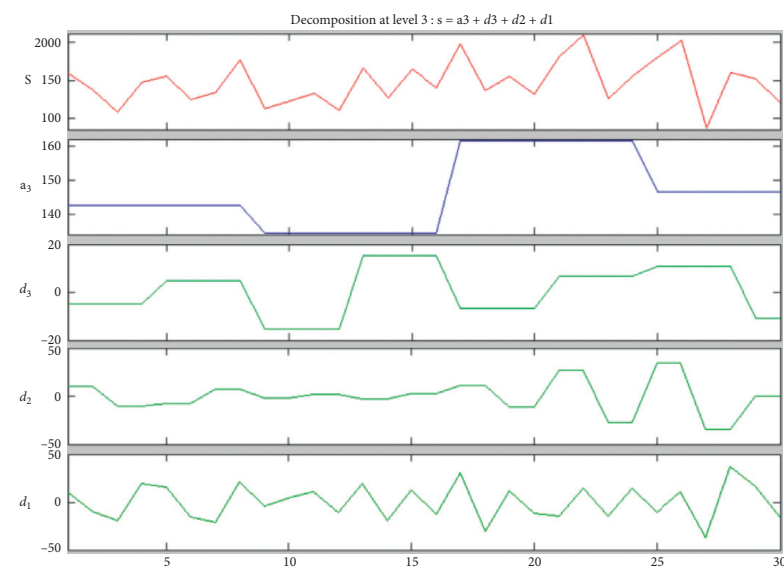

(e)

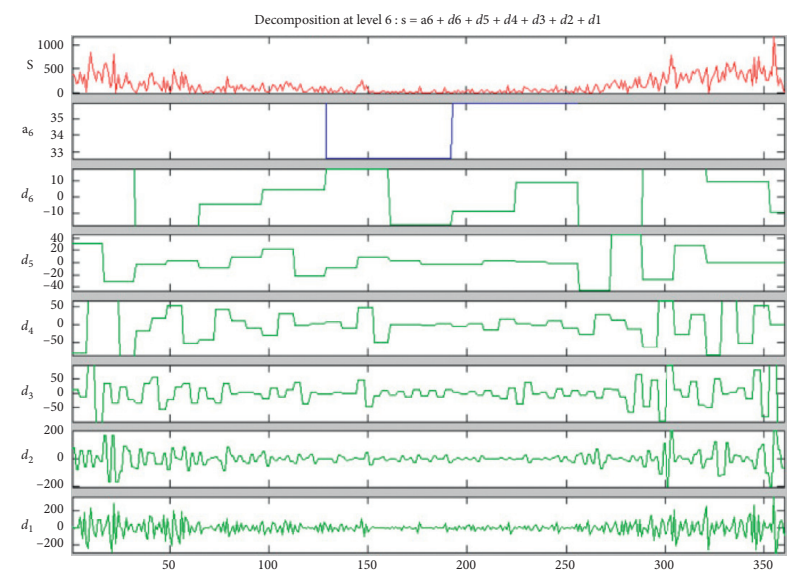

(d)

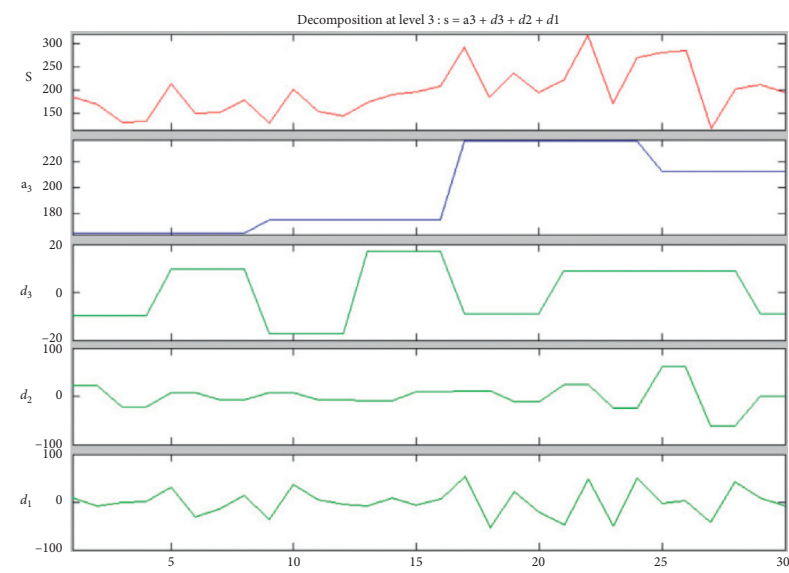

(f)

FiguRE 5: Discrete wavelet transform results for monthly rainfall: (a) for Badulla (monthly); (b) for Ledgerwatte Estate (monthly); (c) for Lower Spring Valley (monthly); (d) for Kandekatiya (monthly); (e) for Badulla (annual); (f) for Ledgerwatte Estate (annual).

TABle 3: Comparison of trend analysis.

\begin{tabular}{|c|c|c|c|}
\hline Test & Monthly & Seasonal & Annual \\
\hline MK & Ledgerwatte Estate: Feb $\uparrow$ and Oct $\uparrow$; Lower Spring Valley: & Ledgerwatte Estate: upward, $2^{\text {nd }} \uparrow$ & Ledgerwatte Estate: $\uparrow$ \\
\hline SQMK & 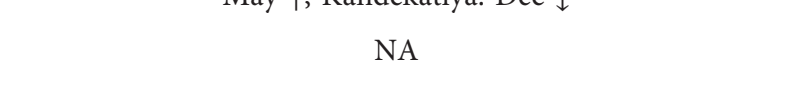 & $\begin{array}{l}\text { Badulla: } 1^{\text {st }} \uparrow \text {; Ledgerwatte Estate: NE } \uparrow \\
\text { and } 1^{\text {st }} \uparrow \text {; Lower spring valley: } 1^{\text {st }} \uparrow\end{array}$ & Ledgerwatte Estate: $\uparrow$ \\
\hline ITA & $\begin{array}{l}\text { Badulla: Mar } \uparrow \text { and Oct } \uparrow \text {; Ledgerwatte Estate: May } \uparrow \text {, Oct } \uparrow \text {, } \\
\text { and Dec } \uparrow \text {; Lower Spring Valley: May } \uparrow \text {; Kandekatiya: Oct } \uparrow\end{array}$ & $\begin{array}{c}\text { Badulla: } 2^{\text {nd }} \uparrow \text {; Ledgerwatte Estate: NE } \uparrow \text {, } \\
1^{\text {st }} \uparrow \text {, and } 2^{\text {nd }} \uparrow \text {; Kandekatiya: SW } \uparrow\end{array}$ & Ledgerwatte Estate \\
\hline CWT & Cyclic patterns in all four gauges & NA & \\
\hline DWT & Cyclic patterns in all four gauges & Cyclic patterns il & $\begin{array}{l}\text { Cyclic patterns in all } \\
\text { four gauges }\end{array}$ \\
\hline
\end{tabular}

interest. Majority of the farmers would have their famous question: "would there be enough water to harvest for the next term?". This would be a million-dollar question to answer. However, the farmers can be advised not only for the potential climatic trends but also cyclic patterns (using CWT and DWT) of the rainfall to the Badulu Oya catchment using this analysis.

\section{Conclusions}

The results revealed positive rainfall trends in Badulu Oya catchment. Farming community in the Badulla district would be interested on the finding. Therefore, it can be predicted that there would not be water scarcities in the catchment in coming recent future. As usual, the MK test 
combined with Sen's slope is proved to be highly efficient in finding the quantitative and qualitative analyses of rainfall trends. However, graphical trends (ITA) provided a quick qualitative view of the trends at a lower computational cost. Therefore, ITA can be considered for similar analysis as the first step in searching rainfall trends. In addition, as it is expected DWT outperformed the CWT. The complexity and computational cost are going to be two important factors for the successful application of the DWT. Therefore, the rainfall patterns can be easily identified by DWT. Therefore, as a summary, rainfall trends for Badulu Oya catchment were successfully presented from this paper while comparing the available trend analysis methods. The authors would like to recommend a set of tests rather a single test in identifying rainfall trends to local catchment to enhance the analysis. Thus, the outcome would be much beneficial to the relevant stakeholders. In addition, it is highly advised to do continuous analysis for the localized catchments while identifying the importance of the climate with the local interest.

\section{Data Availability}

The climatic data and the analysis data are available from the corresponding author upon request.

\section{Disclosure}

The research was carried out in the Sabaragamuwa University, Belihuloya, Sri Lanka, and Sri Lanka Institute of Information Technology, Malabe, Sri Lanka environments. No specific funds were received to carry out this research.

\section{Conflicts of Interest}

The authors declare that they have no conflicts of interest.

\section{Acknowledgments}

The authors would like to acknowledge the support they have received from their home universities.

\section{References}

[1] S. Withanachchi, S. Köpke, C. Withanachchi, R. Pathiranage, and A. Ploeger, "Water Resource Management in Dry Zonal Paddy Cultivation in Mahaweli River Basin, Sri Lanka: An Analysis of Spatial and Temporal Climate Change Impacts and Traditional Knowledge," Climate, vol. 2, no. 4, pp. 329-354, 2014.

[2] C. M. Dunning, E. Black, and R. P. Allan, "Later Wet Seasons with More Intense Rainfall over Africa under Future Climate Change," Journal of Climate, vol. 31, no. 23, pp. 9719-9738, 2018.

[3] H. J. Fowler and M. Ekström, "Multi-model ensemble estimates of climate change impacts on UK seasonal precipitation extremes," International Journal of Climatology, vol. 29, no. 3, pp. 385-416, 2009.

[4] M. K. Van Aalst, "The impacts of climate change on the risk of natural disasters," Disasters, vol. 30, no. 1, pp. 5-18, 2006.
[5] D. Waters, W. E. Watt, J. Marsalek, and B. C. Anderson, "Adaptation of a Storm Drainage System to Accommodate Increased Rainfall Resulting from Climate Change," Journal of Environmental Planning and Management, vol. 46, no. 5, pp. 755-770, 2003.

[6] R. L. Wilby, K. J. Beven, and N. S. Reynard, "Climate change and fluvial flood risk in the UK: more of the same?" $\mathrm{Hy}$ drological Processes, vol. 22, no. 14, pp. 2511-2523, 2008.

[7] J. Huang, M. Ji, Y. Xie, S. Wang, Y. He, and J. Ran, "Global semi-arid climate change over last 60 years," Climate Dynamics, vol. 46, no. 3-4, pp. 1131-1150, 2015.

[8] P. Molnar, "Climate change, flooding in arid environments, and erosion rates," Geology, vol. 29, no. 12, pp. 1071-1074, 2001.

[9] R. Seager, M. Ting, I. Held et al., "Model Projections of an Imminent Transition to a More Arid Climate in Southwestern North America," Science, vol. 316, no. 5828, pp. 1181-1184, 2007.

[10] L. Gimeno, M. Vázquez, J. Eiras-Barca et al., "Recent progress on the sources of continental precipitation as revealed by moisture transport analysis," Earth-Science Reviews, vol. 201, p. 103070, 2020.

[11] K. E. Trenberth, "Conceptual Framework for Changes of Rainfall and Extremes of the Hydrological Cycle with Climate Change," PAGES news, vol. 8, no. 1, pp. 12-13, 2000.

[12] M. Tsagris, A. Alenazi, K.-M. Verrou, and N. Pandis, "Hypothesis testing for two population means: parametric or nonparametric test?" Journal of Statistical Computation and Simulation, vol. 90, no. 2, pp. 252-270, 2019.

[13] N. S. Abeysingha and U. R. L. N. Rajapaksha, "SPI-Based Spatiotemporal Drought over Sri Lanka," Advances in Meteorology, vol. 2020, pp. 1-10, Article ID 9753279, 2020.

[14] M. Amirabadizadeh, Y. F. Huang, and T. S. Lee, "Recent Trends in Temperature and Precipitation in the Langat River Basin, Malaysia," Advances in Meteorology, vol. 2015, pp. 1-16, Article ID 579437, 2015.

[15] T. Merabtene, M. Siddique, and A. Shanableh, "Assessment of Seasonal and Annual Rainfall Trends and Variability in Sharjah City, UAE," Advances in Meteorology, vol. 2016, Article ID 6206238, 13 pages, 2016.

[16] X. Song, J. Zhang, C. Zhang, and X. Zou, "A Comprehensive Analysis of the Changes in Precipitation Patterns over Beijing during 1960-2012," Advances in Meteorology, vol. 2019, pp. 1-22, Article ID 6364040, 2019.

[17] P. Datta and S. Das, "Analysis of long-term seasonal and annual temperature trends in North Bengal, India," Spatial Information Research, vol. 27, no. 4, pp. 475-496, 2019.

[18] L. Mumo, J. Yu, and B. Ayugi, "Evaluation of spatiotemporal variability of rainfall over Kenya from 1979 to 2017," Journal of Atmospheric and Solar-Terrestrial Physics, vol. 194, p. 105097, 2019.

[19] S. Salehi, M. Dehghani, S. M. Mortazavi, and V. P. Singh, "Trend analysis and change point detection of seasonal and annual precipitation in Iran," International Journal of Climatology, vol. 40, no. 1, pp. 308-323, 2019.

[20] S. Sharma and P. K. Singh, "Spatial trends in rainfall seasonality: a case study in Jharkhand, India," Weather, vol. 74, no. 1, pp. 31-39, 2018.

[21] S. Shrestha, T. Yao, and T. R. Adhikari, "Analysis of rainfall trends of two complex mountain river basins on the southern slopes of the Central Himalayas," Atmospheric Research, vol. 215, pp. 99-115, 2019.

[22] T. Caloiero, "Evaluation of rainfall trends in the South Island of New Zealand through the innovative trend analysis (ITA)," 
Theoretical and Applied Climatology2019, vol. 139, no. 1-2, pp. 493-504.

[23] W.D.S. Nisansala, N.S. Abeysingha, A. Islam, and A.M.K.R. Bandara, "Recent rainfall trend over Sri Lanka (1987-2017)," International Journal of Climatology, vol. 40, no. 7, p. 3417, 2019.

[24] U. Rathnayake, "Comparison of Statistical Methods to Graphical Methods in Rainfall Trend Analysis: Case Studies from Tropical Catchments," Advances in Meteorology, vol. 2019, Article ID 8603586, 1 page, 2019.

[25] Y. Wang, Y. Xu, H. Tabari et al., "Innovative trend analysis of annual and seasonal rainfall in the Yangtze River Delta, eastern China," Atmospheric Research2020, vol. 231, Article ID 104673.

[26] H Wu and H Qian, "Innovative trend analysis of annual and seasonal rainfall and extreme values in Shaanxi, China, since the 1950s," International Journal of Climatology, vol. 37, no. 5, pp. 2582-2592, 2016.

[27] N. Joshi, D. Gupta, S. Suryavanshi, J. Adamowski, and C. A. Madramootoo, "Analysis of trends and dominant periodicities in drought variables in India: A wavelet transform based approach," Atmospheric Research, vol. 182, pp. 200-220, 2016.

[28] D. Labat, J. Ronchail, and J. Guyot, "Recent advances in wavelet analyses: Part 2-Amazon, Parana, Orinoco and Congo discharges time scale variability," Journal of Hydrology, vol. 314, no. 1-4, pp. 289-311, 2005.

[29] P. P. Nikhil Raj and P. A. Azeez, "Trend analysis of rainfall in Bharathapuzha River basin, Kerala, India," International Journal of Climatology, vol. 32, no. 4, pp. 533-539, 2011.

[30] T. Partal and M. Küçük, "Long-term trend analysis using discrete wavelet components of annual precipitations measurements in Marmara region (Turkey)," Physics and Chemistry of the Earth, Parts $A / B / C$, vol. 31, no. 18, pp. 1189-1200, 2006.

[31] Y.-F. Sang, D. Wang, J.-C. Wu, Q.-P. Zhu, and L. Wang, "Entropy-Based Wavelet De-noising Method for Time Series Analysis," Entropy, vol. 11, no. 4, pp. 1123-1147, 2009.

[32] R. Mahmood, S. Jia, and W. Zhu, "Analysis of climate variability, trends, and prediction in the most active parts of the Lake Chad basin, Africa," Scientific Reports, vol. 9, no. 1, 2019.

[33] M. Mudelsee, "Trend analysis of climate time series: A review of methods," Earth-Science Reviews, vol. 190, pp. 310-322, 2019.

[34] N. Phojanamongkolkij, S. Kato, B. A. Wielicki, P. C. Taylor, and M. G. Mlynczak, "A Comparison of Climate Signal Trend Detection Uncertainty Analysis Methods," Journal of Climate, vol. 27, no. 9, pp. 3363-3376, 2014.

[35] C. R. Groves, E. T. Game, M. G. Anderson et al., "Incorporating climate change into systematic conservation planning," Biodiversity and Conservation, vol. 21, no. 7, pp. 1651-1671, 2012.

[36] K. E. McNamara and H. J. Des Combes, "Planning for Community Relocations Due to Climate Change in Fiji," International Journal of Disaster Risk Science, vol. 6, no. 3, pp. 315-319, 2015.

[37] A. E. Reside, N. Butt, and V. M. Adams, "Adapting systematic conservation planning for climate change," Biodiversity and Conservation, vol. 27, no. 1, pp. 1-29, 2017.

[38] E. L. Rowland, J. E. Davison, and L. J. Graumlich, “Approaches to Evaluating Climate Change Impacts on Species: A Guide to Initiating the Adaptation Planning Process," Environmental Management, vol. 47, no. 3, pp. 322-337, 2011.
[39] S. Herath and U. Ratnayake, "Monitoring rainfall trends to predict adverse impacts-a case study from Sri Lanka (19641993)," Global Environmental Change, vol. 14, pp. 71-79, 2004.

[40] H. Jayawardene, D. Sonnadara, and D. Jayewardene, "Trends of Rainfall in Sri Lanka over the Last Century," Sri Lankan Journal of Physics, vol. 6, pp. 7-17, 2005.

[41] B. Khaniya, I. Jayanayaka, P. Jayasanka, and U. Rathnayake, "Rainfall Trend Analysis in Uma Oya Basin, Sri Lanka, and Future Water Scarcity Problems in Perspective of Climate Variability," Advances in Meteorology, vol. 2019, pp. 1-10, Article ID 3636158, 2019.

[42] B. Khaniya, H. G. Priyantha, N. Baduge, H. M. Azamathulla, and U. Rathnayake, "Impact of climate variability on hydropower generation: A case study from Sri Lanka," ISH Journal of Hydraulic Engineering, vol. 26, no. 3, pp. 301-309, 2018.

[43] P. Wickramagamage, "Spatial and temporal variation of rainfall trends of Sri Lanka," Theoretical and Applied Climatology, vol. 125, no. 3-4, pp. 427-438, 2015.

[44] P. Ranasinghe, G. Fernando, C. Dissanayake, M. Rupasinghe, and D. Witter, "Statistical evaluation of stream sediment geochemistry in interpreting the river catchment of highgrade metamorphic terrains," Journal of Geochemical Exploration, vol. 103, no. 2-3, pp. 97-114, 2009.

[45] T. Wagalawatta, W. Bebermeier, D. Knitter, K. Kohlmeyer, and B. Schütt, "Ancient rock quarries in Anuradhapura, Sri Lanka," Journal for Ancient Studies, vol. 4, pp. 48-65, 2015.

[46] W. D. T. M. Gunawardhana, J. M. C. K. Jayawardhana, E. P. N. Udayakumara, and S. Malavipathirana, "Spatiotemporal variation of water quality and bio indicators of the Badulu Oya in Sri Lanka due to catchment disturbances," Journal of the National Science Foundation of Sri Lanka, vol. 46, no. 1, pp. 51-67, 2018.

[47] P. Wickramagamage, "Large-scale deforestation for plantation agriculture in the hill country of Sri Lanka and its impacts," Hydrological Processes, vol. 12, no. 13-14, pp. 2015-2028, 1998.

[48] D. Amara, K. Ullah, and Z. Yushu, "Rainfall erosivity estimation for Sierra Leone using non-parametric indices," Theoretical and Applied Climatology, vol. 139, no. 1-2, pp. 221-236, 2019.

[49] Y. Güçlü, "Improved visualization for trend analysis by comparing with classical Mann-Kendall test and ITA," Journal of Hydrology, vol. 584, no. 24674, 2020.

[50] A. Malik and A. Kumar, "Spatio-temporal trend analysis of rainfall using parametric and non-parametric tests: case study in Uttarakhand, India," Theoretical and Applied Climatology, vol. 140, no. 1-2, pp. 183-207, 2020.

[51] S. Meshram, E. Kahya, C. Meshram, M. Ghorbani, B. Ambade, and R. Mirabbasi, "Long-term temperature trend analysis associated with agriculture crops," Theoretical and Applied Climatology, vol. 140, no. 3-4, pp. 1139-1159, 2020.

[52] A. Malik, A. Kumar, A. Najah Ahmed et al., "Application of non-parametric approaches to identify trend in streamflow during 1976-2007 (Naula watershed)," Alexandria Engineering Journal, vol. 59, no. 3, pp. 1595-1606, 2020.

[53] A. Y. Sönmez and S. Kale, "Climate change effects on annual streamflow of Filyos River (Turkey)," Journal of Water and Climate Change, vol. 11, no. 2, pp. 420-433, 2018.

[54] D. Berryman, B. Bobée, D. Cluis, and J. Haemmerli, "Nonparametric tests for trend detection in water quality time series," Journal of the American Water Resources Association, vol. 24, no. 3, pp. 545-556, 1988. 
[55] I. Ahmad, D. Tang, T. Wang, M. Wang, and B. Wagan, "Precipitation Trends over Time Using Mann-Kendall and Spearman's rho Tests in Swat River Basin, Pakistan," Advances in Meteorology, vol. 2015, pp. 1-15, Article ID 431860, 2015.

[56] K. H. Hamed, “The distribution of Spearman's rho trend statistic for persistent hydrologic data," Hydrological Sciences Journal, vol. 61, no. 1, pp. 214-223, 2015.

[57] D. Machiwal and M. Jha, "Trend and homogeneity in subsurface hydrologic variables: case study in a hard-rock aquifer of western india," Hydrologic Time Series Analysis: Theory and Practice, pp. 165-180, Springer, Berlin, Germany, 2012.

[58] Y. Ryu, H. Shin, S. Kim, and J.-H. Heo, "Power Test of Trend Analysis using Simulation Experiment," Journal of Korea Water Resources Association, vol. 46, no. 3, pp. 219-227, 2013.

[59] G. Naveendrakumar, M. Vithanage, H.-H. Kwon, M. C. M. Iqbal, S. Pathmarajah, and J. Obeysekera, "Five Decadal Trends in Averages and Extremes of Rainfall and Temperature in Sri Lanka," Advances in Meteorology, vol. 2018, pp. 1-13, Article ID 4217917, 2018.

[60] A. Panda and N. Sahu, "Trend analysis of seasonal rainfall and temperature pattern in Kalahandi, Bolangir and Koraput districts of Odisha, India," Atmospheric Science Letters, vol. 20, no. 10, pp. 1-10, 2019.

[61] H. B. Mann, "Nonparametric Tests Against Trend," Econometrica, vol. 13, no. 3, pp. 245-259, 1945.

[62] M. G. Kendall, Rank Correlation Methods, Griffin, London, UK, 1975.

[63] R. M. Hirsch and J. R. Slack, "A Nonparametric Trend Test for Seasonal Data With Serial Dependence," Water Resources Research, vol. 20, no. 6, pp. 107-121, 1984.

[64] S. Adarsh and M. Janga Reddy, "Trend analysis of rainfall in four meteorological subdivisions of southern India using nonparametric methods and discrete wavelet transforms," International Journal of Climatology, vol. 35, no. 6, pp. 1107-1124, 2014.

[65] R. Sneyers, On the Statistical Analysis of Series of Observations, Technical Note 143, WMO-No. 415, p. 192, World Meteorological Organization (WMO), Geneva, Switzerland, 1990.

[66] M. Zarenistanak, A. G. Dhorde, and R. H. Kripalani, "Trend analysis and change point detection of annual and seasonal precipitation and temperature series over southwest Iran," Journal of Earth System Science, vol. 123, no. 2, pp. 281-295, 2014.

[67] Z. Sen, "Innovative Trend Analysis Methodology," Journal of Hydrologic Engineering, vol. 17, pp. 1042-1046, 2012.

[68] B. K. Pandey, H. Tiwari, and D. Khare, "Trend analysis using discrete wavelet transform (DWT) for long-term precipitation (1851-2006) over India," Hydrological Sciences Journal, vol. 62, no. 13, pp. 2187-2208, 2017.

[69] E.-B. Lin and P. C. Liu, "A discrete wavelet analysis of freak waves in the ocean," Journal of Applied Mathematics, vol. 2004, no. 5, pp. 379-394, 2004.

[70] H. Jia and D. Pan, "Drought Risk Assessment in Yunnan Province of China Based on Wavelet Analysis," Advances in Meteorology, vol. 2016, pp. 1-10, Article ID 1579415, 2016.

[71] Y. Chen, Y. Guan, G. Shao, and D. Zhang, "Investigating Trends in Streamflow and Precipitation in Huangfuchuan Basin with Wavelet Analysis and the Mann-Kendall Test," Water, vol. 8, no. 3-77, pp. 1-32, 2016.

[72] D. Nalley, J. Adamowski, and B. Khalil, "Using discrete wavelet transforms to analyze trends in streamflow and precipitation in Quebec and Ontario (1954-2008)," Journal of Hydrology, vol. 475, pp. 204-228, 2012.
[73] C. Chou, "Applying multi-resolution analysis to differential hydrological grey models with dual series," Journal of Hydrology, vol. 332, no. 1-2, pp. 174-186, 2007.

[74] C. A. Guimarães Santos and G. B. L. d. Silva, "Daily streamflow forecasting using a wavelet transform and artificial neural network hybrid models," Hydrological Sciences Journal, vol. 59, no. 2, pp. 312-324, 2014.

[75] C. Santos, P. Freire, R. Silva, and S. Akrami, "Hybrid Wavelet Neural Network Approach for Daily Inflow Forecasting Using Tropical Rainfall Measuring Mission Data," Journal of Hydrologic Engineering, vol. 24, no. 2, Article ID 04018062, 2019.

[76] S. Sharma, D. Nalley, and N. Subedi, "Characterization of Temporal and Spatial Variability of Phosphorus Loading to Lake Erie from the Western Basin Using Wavelet Transform Methods," Hydrology, vol. 5, no. 3-50, pp. 1-28, 2018.

[77] M. Yang, Y. Sang, C. Liu, and Z. Wang, "Discussion on the Choice of Decomposition Level for Wavelet Based Hydrological Time Series Modeling," Water, vol. 8, no. 5-197, pp. 1-11, 2016.

[78] F. Zhang, H. Dai, and D. Tang, "A Conjunction Method of Wavelet Transform-Particle Swarm Optimization-Support Vector Machine for Streamflow Forecasting," Journal of Applied Mathematics, vol. 2014, Article ID 910196, 10 pages, 2014.

[79] T. Zhao, L. Wu, D. Li, and Y. Ding, "Multifractal Analysis of Hydrologic Data Using Wavelet Methods and Fluctuation Analysis," Discrete Dynamics in Nature and Society, vol. 2017, Article ID 3148257, 18 pages, 2017. 